\title{
Effect of Acoustic Energy on Fluidization of Ultra-Fine Particle
}

\author{
Gagandeep Singh Theti ${ }^{*}$, Pramod E. Chaudhari ${ }^{\dagger}$ and Rupesh J. Yadav ${ }^{\dagger}$ \\ †Mechanical Department, MIT College of Engineering, Pune, India \\ Accepted 02 March 2016, Available online 15 March 2016, Special Issue-4 (March 2016)
}

\begin{abstract}
Achieving fine particles to fluidize are very difficult with conventional methods, due to strong inter particle attraction. The difficulty of putting these powders in suspension in the fluidizing gas is related to the cohesive structure and, interparticular force, to the physical forces between the primary particles. Large inter particle forces lead to bed cracking, slugging and channeling, and cause the powder not to fluidize consistently. In this study the fluidization behavior of fume silica and talc of micronic diameter belonging to the group $C$ of Geldart's classification has been investigated. The basic aim of this research work is to improve the quality of fluidization of fume silica $(d p=45 \mu \mathrm{m})$ and talc $(d p=10-75 \mu \mathrm{m})$ by applying external source in terms of acoustic field. In addition, effect of acoustic field and variation of frequency on minimum fluidization velocity (Umf) and on minimum bubbling velocity has been found out. It was observed that Umf decreases in presence of acoustic field with homogenous fluidization. The best effect observed at $145 \mathrm{~dB}$ and $120 \mathrm{~Hz}$.Fluidization under acoustic field allows to partly overcoming the adhesive forces between powders. The fluidization behavior has been improved for the highest sound intensity.
\end{abstract}

Keywords: Fluidization, Geldart's classification, minimum fluidization velocity (Umf),

\section{Introduction}

Fluidization (or fluidisation) is a process similar to liquefaction whereby a granular material is converted from a static solid-like state to a dynamic fluid-like state. This process occurs when a fluid (liquid or gas) is passed up through the granular material.

In the last years, fluidization has progressed through systematic research, with various specialized functions such as: combustion, mixing, chemical reaction, heat and mass transfer, coating, granulation, encapsulation and CVD (Chemical Vapor Deposition) processes. This research development persuaded the researchers to become interested in the use of fine powders (cohesive powder), micronic and nanometric powders. In general, the experiments are complex during the handling or fluidizing of these powders. This is due to the unpredictable behavior of the cohesive powders. The complexity of this behavior is due to the small size of the fine particles, i.e., the micronic or nanometric particles. These tend to form agglomerates (self agglomeration) of completely random size and shape by the action of the interparticle forces between the primary particles. This strong interaction between the powders affects the flow properties of the powders. The smooth fluidization of gas-solid particles is the result of equilibrium between the hydrodynamic, gravitational and interparticle forces. However, in the case of cohesive powders, the interparticle forces are considerable and they control the behavior of a bed composed of fine particles.

Thus, during fluidization, the bed of powder cracks into large portions and the gas tends to flow into the gap between the fissures. For this, it is necessary to apply either a high gas velocity compared to the velocity necessary for fluidizing primary particles, or a lower velocity but with addition of external energy like vibration, magnetic pulsation and acoustic energy to disintegrate the cohesive structure and to facilitate the fluidization of the agglomerates. The mechanism of agglomerate fluidization supposes the passage from group C to group A powder or even a group B powder of the Geldart classification.

\section{The Geldart'S Classification}

Depending on the process requirements, the particle size of the solid material ranges from several microns, e.g. catalytic cracking of hydrocarbons, up to several millimeters in a spouted bed, e.g. for the drying of wheat (1). Solid particles exhibit distinctive fluidization behaviors as a function of size and density. In the early 1970s, Geldart classified particles into four groups: Group A for aeratable particles, Group B for bubbling particles, Group C for cohesive particles and Group D for large spoutable particles. Extensive research has been undertaken on the gas fluidization of 
'classical' particles in the size range of 30-1000 mm (falling under Geldart group A and B particles), and consequently, their fluidization behavior is well understood. Being able to process fine or ultrafine materials is advantageous because their small size and large-surface-area ratio allows good interparticle contact, and hence enhanced reaction efficiency. As a consequence, from the mid-1980s, research on the fluidization behavior of fine and ultrafine (nano-sized) particles has become more popular, predominantly in pharmaceutical and materials science applications, e.g. coatings, electronics, ceramics and catalysis .The fluidization of nanoparticles, which has more complex behavior due to strong interparticle interactions (such as Van der Waals, electrostatic and moisture-induced surface tension forces), is more difficult to achieve. Under such conditions, the gas tends to flow through fixed paths, called stable channels. Several researchers successfully fluidized nanoparticles by employing various external force assistances, e.g. electromagnetic field, acoustic and mechanical agitation and centrifugal field. Among those, mechanical vibration can significantly reduce the occurrence of channeling compared to that in the conventional fluidized beds. other advantages include reduced minimum fluidization velocity and elutriation. Most of the works published thus far on the vibration-assisted fluidization of nanoparticles were limited to the vertical configuration and higher frequencies between 30 and $200 \mathrm{~Hz}$. As a consequence, the information on the full potential of vibrofluidisation (i.e. lower limit of frequency, vibration configurations) was insufficient to this end. In this study we use acoustic /sound energy with sound pressure level of about $145 \mathrm{~dB}$ and $120 \mathrm{~Hz}$

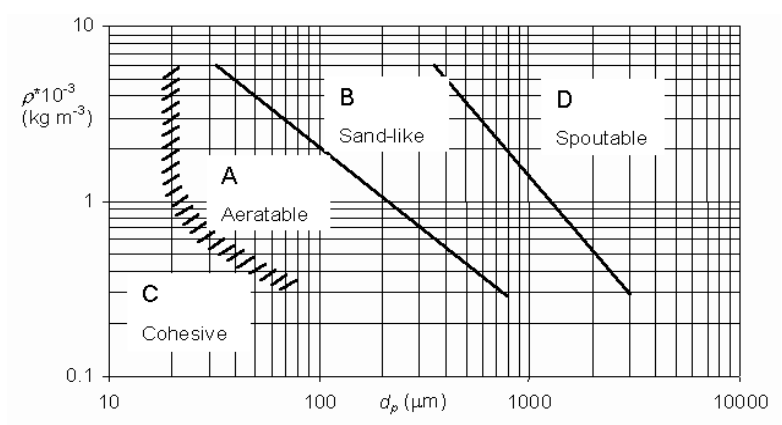

Figure 2

\section{Experimental Details}

A schematic diagram of the sound-assisted fluidization system is shown in Fig. 3. The system consists of a fluidized bed of nanoparticle agglomerates, a sound excitation device and a visualization apparatus. The fluidized bed is a vertical transparent column with a distributor at the bottom. The column is a section of acrylic pipe with an inner diameter of $18 \mathrm{~cm}$ and a height of $910 \mathrm{~mm}$. The distributor is a sintered metal plate of stainless steel with a thickness of $2 \mathrm{~mm}$ and pore size of $20 \mathrm{Am}$. An ultrafine mesh filter is located at the gas outlet to filter out any elutriated nanoparticle agglomerates. A 8 inch dia. loudspeaker, powered by a sound excitation system (HI-FI stereo amplifier) with a signal generator, is installed on the top of the fluidized bed. A precision sound pressure level meter is used to measure the sound pressure level. The sound excitation system is capable of generating a sound wave in the fluidized bed with a sound pressure level up to $125 \mathrm{~dB}$. The sound frequency from the signal generator can be adjusted from 11.4 to $0.9 \mathrm{MHz}$ The fluidization behavior is visualized with the aid of a lighting device. Atmospheric compressed air is used as the fluidizing gas. The air flow rate is measured and adjusted by a calibrated rotameter. Four rotameter with different flow rates of 100 LPM, 50 LPM,25 LPM,10 LPM \& 5 LPM. A double-acting multi-stage compressor of $10 \mathrm{HP}$ motor with pressure capacity of 7 bar is used for introducing the compressed air in the fluidized column. With the aid of an $U$ - tube manometer, the pressure drop across the bed is measured, which excludes the pressure drop over the distributor. The fig no.3 shows the complete setup layout of the apparatus.

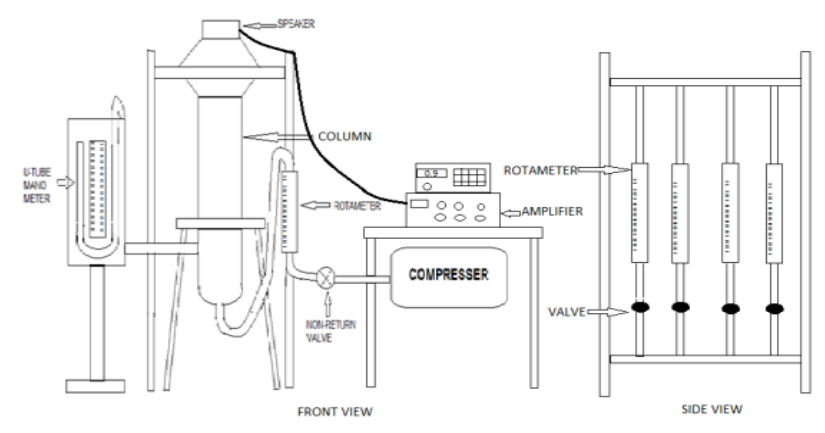

Figure 3

\section{Test materials}

1. Material: Silica $\left(\mathrm{SiO}_{2}\right)$

Table 1 Without acoustic energy

\begin{tabular}{|c|c|c|c|c|}
\hline $\begin{array}{c}\text { Sr. } \\
\text { No. }\end{array}$ & $\begin{array}{c}\text { Air } \\
\text { Velocity } \\
\mathrm{m} / \mathrm{sec} \\
\times 10^{3}\end{array}$ & $\begin{array}{c}\text { Air Flow } \\
\text { Rate } \\
\mathrm{lpm}\end{array}$ & $\begin{array}{c}\text { Pressure } \\
\operatorname{Diff}(\Delta \mathrm{p}) \\
\mathrm{cm}\end{array}$ & $\begin{array}{c}\text { Bed } \\
\text { suspensio } \\
\mathrm{n} \\
(\mathrm{h}) \mathrm{Cm}\end{array}$ \\
\hline 1 & 2.12 & 1 & 2 & 11.8 \\
\hline 2 & 4.24 & 2 & 2.8 & 12 \\
\hline 3 & 6.36 & 3 & 3.2 & 12.3 \\
\hline 4 & 8.48 & 4 & 3.7 & 12.5 \\
\hline 5 & 10.6 & 5 & 3.9 & 12.9 \\
\hline 6 & 12.72 & 6 & 4.7 & 14.3 \\
\hline 7 & 14.84 & 7 & 4.8 & 14.8 \\
\hline 8 & 16.96 & 8 & 5 & 15.2 \\
\hline 9 & 19.08 & 9 & 5.3 & 15.8 \\
\hline 10 & 21.3 & 10 & 6 & 16.8 \\
\hline
\end{tabular}


Table 2 With acoustic energy at $90 \mathrm{~Hz}$

\begin{tabular}{|c|c|c|c|c|}
\hline $\begin{array}{c}\text { Sr. } \\
\text { No. }\end{array}$ & $\begin{array}{c}\text { Air } \\
\text { Velocity } \\
\mathrm{m} / \mathrm{sec} \\
\times 10^{3}\end{array}$ & $\begin{array}{c}\text { Air } \\
\text { Flow } \\
\text { Rate } \\
\mathrm{lpm}\end{array}$ & $\begin{array}{c}\text { Pressure } \\
\text { Difference } \\
(\Delta \mathrm{p}) \\
\mathrm{cm}\end{array}$ & $\begin{array}{c}\text { Bed } \\
\text { Suspension } \\
(\mathrm{h}) \\
\mathrm{cm}\end{array}$ \\
\hline 1 & 2.12 & 1 & 4.6 & 11.7 \\
\hline 2 & 4.24 & 2 & 5 & 12.8 \\
\hline 3 & 6.36 & 3 & 5.1 & 13.7 \\
\hline 4 & 8.48 & 4 & 5.3 & 14.2 \\
\hline 5 & 10.6 & 5 & 5.5 & 14.9 \\
\hline 6 & 12.72 & 6 & 5.7 & 15.4 \\
\hline 7 & 14.84 & 7 & 6 & 15.8 \\
\hline 8 & 16.96 & 8 & 6.35 & 16 \\
\hline 9 & 19.08 & 9 & 6.7 & 16.8 \\
\hline 10 & 21.3 & 10 & 7.1 & 17.1 \\
\hline
\end{tabular}

Table 3 With acoustic energy at $110 \mathrm{~Hz}$

\begin{tabular}{|c|c|c|c|c|}
\hline $\begin{array}{c}\text { Sr. } \\
\text { No. }\end{array}$ & $\begin{array}{c}\text { Air } \\
\text { Velocity } \\
\mathrm{m} / \mathrm{sec} \\
\times 10^{3}\end{array}$ & $\begin{array}{c}\text { Air } \\
\text { Flow } \\
\text { Rate } \\
\mathrm{lpm}\end{array}$ & $\begin{array}{c}\text { Pressure } \\
\text { Difference }(\Delta \mathrm{p}) \\
\mathrm{cm}\end{array}$ & $\begin{array}{c}\text { Bed } \\
\text { Suspension } \\
(\mathrm{h}) \\
\mathrm{Cm}\end{array}$ \\
\hline 1 & 2.12 & 1 & 4.6 & 12 \\
\hline 2 & 4.24 & 2 & 4.9 & 13.1 \\
\hline 3 & 6.36 & 3 & 5.1 & 13.9 \\
\hline 4 & 8.48 & 4 & 5.2 & 14.5 \\
\hline 5 & 10.6 & 5 & 5.3 & 14.9 \\
\hline 6 & 12.72 & 6 & 5.5 & 15.5 \\
\hline 7 & 14.84 & 7 & 5.9 & 16 \\
\hline 8 & 16.96 & 8 & 6.1 & 16.5 \\
\hline 9 & 19.08 & 9 & 6.5 & 16.9 \\
\hline 10 & 21.3 & 10 & 6.8 & 17.2 \\
\hline
\end{tabular}

Table 4 With acoustic energy at $140 \mathrm{~Hz}$

\begin{tabular}{|c|c|c|c|c|}
\hline $\begin{array}{c}\text { Sr. } \\
\text { No. }\end{array}$ & $\begin{array}{c}\text { Air } \\
\text { Velocity } \\
\mathrm{m} / \mathrm{sec} \\
\times 10^{3}\end{array}$ & $\begin{array}{c}\text { Air } \\
\text { Flow } \\
\text { Rate } \\
\mathrm{lpm}\end{array}$ & $\begin{array}{c}\text { Pressure } \\
\text { Difference }(\Delta \mathrm{p}) \\
\mathrm{cm}\end{array}$ & $\begin{array}{c}\text { Bed } \\
\text { suspension(h) } \\
\mathrm{cm}\end{array}$ \\
\hline 1 & 2.12 & 1 & 4.2 & 11.6 \\
\hline 2 & 4.24 & 2 & 4.8 & 13 \\
\hline 3 & 6.36 & 3 & 4.9 & 13.3 \\
\hline 4 & 8.48 & 4 & 5.2 & 13.8 \\
\hline 5 & 10.6 & 5 & 5.3 & 14.2 \\
\hline 6 & 12.72 & 6 & 5.7 & 14.8 \\
\hline 7 & 14.84 & 7 & 5.9 & 15 \\
\hline 8 & 16.96 & 8 & 6.2 & 15.2 \\
\hline 9 & 19.08 & 9 & 6.7 & 15.6 \\
\hline 10 & 21.3 & 10 & 7.1 & 16.1 \\
\hline
\end{tabular}

On X-axis-Air velocity in $\mathrm{m} / \mathrm{Sec}\left(\times 10^{-3}\right)$

On Y-axis- $\Delta \mathrm{P}$ (Pressure Difference in $\mathrm{cm}$ )

Silica

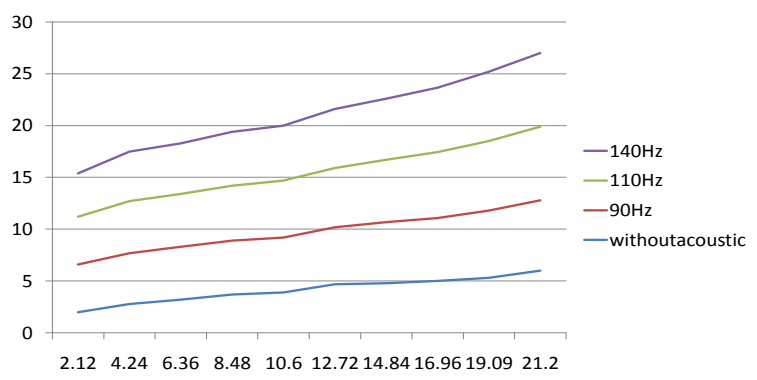

2. Material: Talc powder $(\mathrm{Mg} 3 \mathrm{Si} 4010(\mathrm{OH}) 2$

Hydrous Magnesium Silicate

Magnesium Silicate Hydroxide

Table 5 With acoustic energy at $90 \mathrm{~Hz}$

\begin{tabular}{|c|c|c|c|c|}
\hline $\begin{array}{c}\text { Sr. } \\
\text { No. }\end{array}$ & $\begin{array}{c}\text { Air } \\
\text { Velocity } \\
\mathrm{m} / \mathrm{sec} \\
\times 10^{3}\end{array}$ & $\begin{array}{c}\text { Air Flow } \\
\text { Rate } \\
\mathrm{lpm}\end{array}$ & $\begin{array}{c}\text { Pressure } \\
\text { Difference }(\Delta \mathrm{p}) \\
\mathrm{cm}\end{array}$ & $\begin{array}{c}\text { Bed } \\
\text { Suspension } \\
(\mathrm{h}) \mathrm{Cm}\end{array}$ \\
\hline 1 & 1.06 & 0.5 & 5.8 & 11.9 \\
\hline 2 & 2.12 & 1 & 5.9 & 13 \\
\hline 3 & 4.24 & 2 & 6 & 13 \\
\hline 4 & 6.36 & 3 & 6 & 13 \\
\hline 5 & 8.48 & 4 & 6 & 13.1 \\
\hline 6 & 10.6 & 5 & 5.8 & 14 \\
\hline 7 & 15.9 & 7.5 & 6 & 15 \\
\hline 8 & 21.5 & 10 & 8 & 26 \\
\hline 9 & 26.5 & 12.5 & 8 & 29 \\
\hline 10 & 31.8 & 15 & 8.4 & 30.5 \\
\hline 11 & 37.1 & 17.5 & 8.8 & 31 \\
\hline 12 & 42.4 & 20 & 9 & 31 \\
\hline
\end{tabular}

Table 6 With acoustic energy at $110 \mathrm{~Hz}$

\begin{tabular}{|c|c|c|c|c|}
\hline $\begin{array}{c}\text { Sr. } \\
\text { No. }\end{array}$ & $\begin{array}{c}\text { Air } \\
\text { Velocity } \\
\mathrm{m} / \mathrm{sec} \\
\times 10^{3}\end{array}$ & $\begin{array}{c}\text { Air } \\
\text { Flow } \\
\text { Rate } \\
\mathrm{lpm}\end{array}$ & $\begin{array}{c}\text { Pressure } \\
\text { Difference }(\Delta \mathrm{p}) \\
\mathrm{cm}\end{array}$ & $\begin{array}{c}\text { Bed } \\
\text { Suspensi } \\
\text { on } \\
(\mathrm{h}) \mathrm{Cm}\end{array}$ \\
\hline 1 & 1.06 & 0.5 & 4.8 & 11.6 \\
\hline 2 & 2.12 & 1 & 5 & 11.5 \\
\hline 3 & 4.24 & 2 & 4.8 & 12 \\
\hline 4 & 6.36 & 3 & 4.8 & 12 \\
\hline 5 & 8.48 & 4 & 4.8 & 12.1 \\
\hline 6 & 10.6 & 5 & 4.9 & 12.5 \\
\hline 7 & 15.9 & 7.5 & 5.6 & 14.5 \\
\hline 8 & 21.5 & 10 & 7.2 & 24.5 \\
\hline 9 & 26.5 & 12.5 & 7.4 & 25.5 \\
\hline 10 & 31.8 & 15 & 7.9 & 26 \\
\hline 11 & 37.1 & 17.5 & 8.2 & 28 \\
\hline 12 & 42.4 & 20 & 8.8 & 29 \\
\hline 13 & 47.5 & 22.5 & 9 & 29.5 \\
\hline 14 & 53 & 25 & 9 & 30 \\
\hline
\end{tabular}

Table 7 With acoustic energy at $140 \mathrm{~Hz}$

\begin{tabular}{|c|c|c|c|c|}
\hline $\begin{array}{c}\text { Sr. } \\
\text { No. }\end{array}$ & $\begin{array}{c}\text { Air } \\
\text { Velocity } \\
\mathrm{m} / \mathrm{sec} \\
\times 10^{3}\end{array}$ & $\begin{array}{c}\text { Air } \\
\text { Flow } \\
\text { Rate } \\
\text { lpm }\end{array}$ & $\begin{array}{c}\text { Pressure } \\
\text { Difference }(\Delta \mathrm{p}) \\
\mathrm{cm}\end{array}$ & $\begin{array}{c}\text { Bed } \\
\text { Suspension } \\
(\mathrm{h}) \\
\mathrm{Cm}\end{array}$ \\
\hline 1 & 1.06 & 0.5 & 6.2 & 11.4 \\
\hline 2 & 2.12 & 1 & 5 & 12 \\
\hline 3 & 4.24 & 2 & 5.3 & 14.5 \\
\hline 4 & 6.36 & 3 & 5.8 & 15 \\
\hline 5 & 8.48 & 4 & 6 & 16.8 \\
\hline 6 & 10.6 & 5 & 6.1 & 17 \\
\hline 7 & 15.9 & 7.5 & 6.8 & 21 \\
\hline 8 & 21.5 & 10 & 7.4 & 25.5 \\
\hline 9 & 26.5 & 12.5 & 8 & 27 \\
\hline 10 & 31.8 & 15 & 8.2 & 28 \\
\hline 11 & 37.1 & 17.5 & 8.9 & 28 \\
\hline 12 & 42.4 & 20 & 9 & 28 \\
\hline 13 & 47.5 & 22.5 & 9.8 & \\
\hline 14 & 53 & 25 & 9.8 & 28 \\
\hline
\end{tabular}


Table 8 Without acoustic energy

\begin{tabular}{|c|c|c|c|c|}
\hline $\begin{array}{c}\text { Sr. } \\
\text { No. }\end{array}$ & $\begin{array}{c}\text { Air } \\
\text { Velocity } \\
\mathrm{m} / \mathrm{sec} \\
\times 10^{3}\end{array}$ & $\begin{array}{c}\text { Air Flow } \\
\text { Rate } \\
\mathrm{lpm}\end{array}$ & $\begin{array}{c}\text { Pressure } \\
\text { Difference } \\
(\Delta \mathrm{p}) \\
\mathrm{cm}\end{array}$ & $\begin{array}{c}\text { Bed } \\
\text { Suspension } \\
(\mathrm{h}) \\
\mathrm{Cm}\end{array}$ \\
\hline 1 & 1.06 & 0.5 & 4 & 13.9 \\
\hline 2 & 2.12 & 1 & 4.6 & 15 \\
\hline 3 & 4.24 & 2 & 4.9 & 15.2 \\
\hline 4 & 6.36 & 3 & 5.1 & 14.2 \\
\hline 5 & 8.48 & 4 & 5.1 & 14 \\
\hline 6 & 10.6 & 5 & 5.3 & 14 \\
\hline 7 & 15.9 & 7.5 & 5.4 & 14.2 \\
\hline 8 & 21.5 & 10 & 5.5 & 14.7 \\
\hline 9 & 26.5 & 12.5 & 5.6 & 14.8 \\
\hline 10 & 31.8 & 15 & 5.2 & 14.9 \\
\hline 11 & 37.1 & 17.5 & 5.4 & 14.9 \\
\hline 12 & 42.4 & 20 & 5.6 & 15.5 \\
\hline 13 & 47.5 & 22.5 & 5.6 & 15.7 \\
\hline 14 & 53 & 25 & 5.6 & 15.7 \\
\hline 15 & 58.3 & 30 & 5.6 & 15.7 \\
\hline
\end{tabular}

Talc

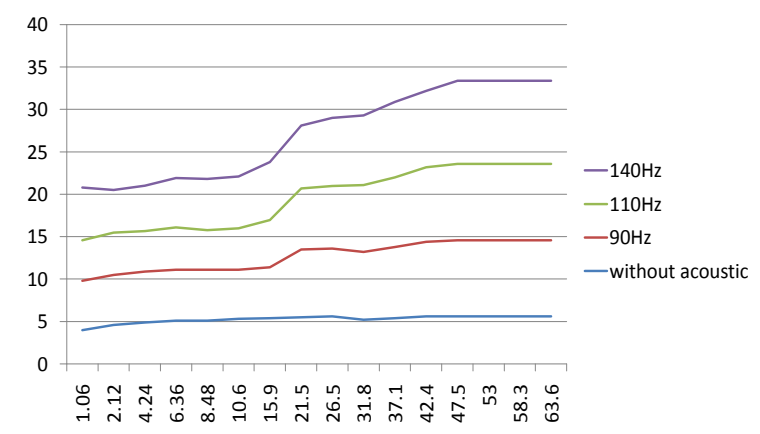

On X-axis-Air velocity in $\mathrm{m} / \mathrm{Sec}\left(\times 10^{-3}\right)$

On Y-axis- $\Delta \mathrm{P}$ (Pressure Difference in $\mathrm{cm}$ )

\section{Result}

Comparative experiment showed that the interaction of acoustic waves with the bulk of solid when group B particle is used. Experiments were conducted by increasing and decreasing gas velocity by measuring bed height. Visual observation shows that bed settles at faster rate and elutriation occurs at higher superficial gas velocity with increase in bubble size. Fluidization properties of glass bed with sound intensity: The present investigation was work out from sound frequency from $90 \mathrm{~Hz}$ to $150 \mathrm{~Hz}$. The glass bed was used in an acoustic fluidized bed. When sound was turned on, the quality of fluidization improved. It was also seen that, the rate of elutriation and bubble size reduces compared to no sound condition. This effect may be due to addition of sound pressure. It indicates sound intensity shows good effect on group B particles at higher level with enhanced quality of fluidization and bed expansion. The sound intensity at $150 \mathrm{~Hz}$ and $80 \mathrm{~dB}$ had the strongest effect on minimum fluidization velocity because $150 \mathrm{~Hz}$ was the resonant frequency for this bed height. The best effect observed at resonance condition with marginally increase in bed height. In addition, minimum fluidization velocity reduces after applying sound at higher level shown in graphs.
Bed expansion in presence of sound intensity

One of the main advantages of acoustic field is to improve quality of fluidization. The bed was tested upto higher sound pressure level of $80 \mathrm{~dB}$ and $\mathrm{L} / \mathrm{D}$ at 5.5. In case of group B particle interparticle attraction is very poor and fluidization start without channeling due to absence of agglomeration. However, bed expansion was not so good compare to group C particle; reported by Nowak et al (1993). Possible reason is that particle allows easy passage to gas to reach upto the surface, because of large particle size and density. The data presented for bed expansion was taken for increasing and decreasing gas velocity. Graph with bed expansion shows different bed expansion with variation in gas velocity for resonance frequency of $90,110,130 \& 140 \mathrm{~Hz}$ for sound intensity of $70 \mathrm{~dB}$ to $80 \mathrm{~dB}$. It was observed that, from increasing gas velocity diagrams shows some different trends of curves. The reverse may be true when curves obtained for increasing and decreasing gas velocity coincide at higher sound intensity i.e. at $140 \mathrm{~dB}$. Under these, condition more homogenous fluidization took place with reduction in voidage. Bed settling was in presence of sound, as the sound wave does not allow the particle to settle at faster rate.

\section{Conclusion}

It was an attempt to study the effect of sound intensity on bed expansion of group B particle, which was not done before. There was an improvement in quality of fluidization, but bed expansion was small, at higher sound intensity. Maximum effect was observed at resonant condition. The minimum fluidization velocity was decreased with less elutriation; further bed setting was comparatively slow when compared to without sound condition. This preliminary study has shown that nanoparticle agglomerates can be easily and smoothly fluidized with the assistance of sound. Since there is a significant reduction in the minimum fluidization velocity in the presence of sound, elutriation of nanoparticle agglomerates becomes much reduced. The ability to fluidize these fumed silica nanoparticle agglomerates can only be achieved within a given range of sound frequency with a sound pressure level above a critical value. Bubbling fluidization occurs within an even smaller range of sound frequency.

\section{References}

Chaouki, C. Chavarie, D. Klvana, Effect of interparticle forces on the hydrodynamic behavior of fluidized aerogels, Powder Technol. 43 (1985) 117-125.

Morooka, K. Kusakabe, A. Kobata, Y. Kato, Fluidization state of ultrafine powders, J. Chem. Eng. Jpn. 21 (1) (1988) 41- 46.

Chirone, L. Massimilla, S. Russo, Bubbling fluidization of a cohesive powder in an acoustic field, Fluidization VII (1992) 545-553

D. Morse, Sonic energy in granular solid fluidization, Ind. Eng. Chem. 47 (6) (1955) 1170- 1175. 
Russo, R. Chirone, L. Massimilla, S. Russo, The influence of the frequency of acoustic waves on sound-assisted fluidization of beds of fine particles, Powder Technol. 82 (1995) 219230.

Nam, R. Pfeffer, R.N. Dave, S. Sundaresan, AIChE J. (2004) (in press)

Chirone, L. Massimilla, S. Russo, Bubble-free fluidization of a cohesive powder in an acoustic field, Chem. Eng. Sci. 48 (1) (1993) 41-53.

Chirone, P. Russo, Resonant behavior of cluster- subcluster structures in sound assisted fluidization beds, Fluidization VIII (1995) 389-397.

Chirone, L. Massimilla, Sound-assisted aeration of beds of cohesive solids, Chem. Eng. Sci. 49 (8) (1994) 1185- 1194.

K. Levy, H. Shnitzer, T. Masaki, J. Salmento, Effect of an acoustic field on bubbling in a gas fluidized bed, Powder Technol. 90 (1997)53-57.

Matsuda, H. Hatano, T. Muramota, A. Tsutsumi, Particle and bubble behavior in ultrafine particle fluidization with high G, Fluidization X, Eng. Foundrym. (2001) 501- 508.

Matsuda, H. Hatano, A. Tsutsumi, Ultrafine particle fluidization and its application to photocatalytic Nox treatment, Chem. Eng. J. 82 (2001) 183-188.

Y. Wang, F. Wei, Y. Jin, T. Luo, Agglomerate particulate fluidization and E-particles, Proceedings of the Third Joint China/USA Chemical Engineering Conference (CUChE-3), 12-006, Beijing, 2000.
Y. Wang, F. Wei, Y. Jin, T. Luo, Bed collapse behavior of primary nanoparticles, in: M. Kwauk, J. Li, and W.-C. Yang (Eds.), Proceedings of the Tenth Engineering Foundation Conference on Fluidization, United Engineering Foundation, New York, USA, Fluidization X, (2001) 477- 484 .

S. Matsuda, H. Hatano, A. Tsutsumi, Modeling for size reduction of agglomerates in nanoparticle fluidization, AIChE 2002 Annual Meeting, November 3 -8, Indianapolis, Indiana, 2002, 138e.

Y.Wang, G. Gu, F.Wei, J.Wu, Fluidization and agglomerate structure of $\mathrm{SiO} 2$ nanoparticles, Powder Technol. 124 (2002) 152-159.

Nam, R. Pfeffer, Aeration vibrofluidization of nanoparticles, AIChE 2002 Annual Meeting, November 3 -8, Indianapolis, Indiana, 2002

R. Pfeffer, R.N. Dave, personal communication (2003). C.A. Herrera, E.K. Levy, Bubbling characteristics of soundassisted fluidized beds, Powder Technol. 119 (2001) 229240.

C.A. Herrera, E.K. Levy, Characteristics of acoustic standing waves in fluidized beds, AIChE J. 48 (3) (2008) 503- 513 